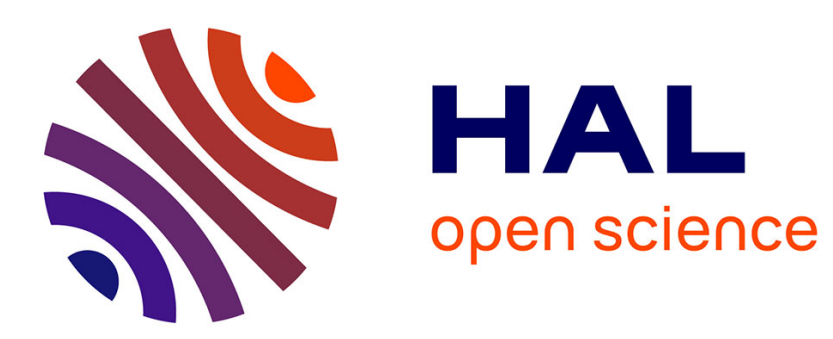

\title{
Magneto-Optical Effects and Electrical Resistivity of La0.8-xBixSr0.2MnO3 Films
}

Y. Yokoyama, K. Ando, M. Umeda, W. Zaets, T. Hirano, I. Solovyev, Y. Suzuki

\section{- To cite this version:}

Y. Yokoyama, K. Ando, M. Umeda, W. Zaets, T. Hirano, et al.. Magneto-Optical Effects and Electrical Resistivity of La0.8-xBixSr0.2MnO3 Films. Journal de Physique IV Proceedings, 1997, 07 (C1), pp.C1643-C1-644. 10.1051/jp4:19971266 . jpa-00254976

\section{HAL Id: jpa-00254976 https://hal.science/jpa-00254976}

Submitted on 1 Jan 1997

HAL is a multi-disciplinary open access archive for the deposit and dissemination of scientific research documents, whether they are published or not. The documents may come from teaching and research institutions in France or abroad, or from public or private research centers.
L'archive ouverte pluridisciplinaire HAL, est destinée au dépôt et à la diffusion de documents scientifiques de niveau recherche, publiés ou non, émanant des établissements d'enseignement et de recherche français ou étrangers, des laboratoires publics ou privés. 


\title{
Magneto-Optical Effects and Electrical Resistivity of $\mathrm{La}_{0.8-x} \mathrm{Bi}_{x} \mathrm{Sr}_{0.2} \mathrm{MnO}_{3}$ Films
}

\author{
Y. Yokoyama, K. Ando, M. Umeda, W. Zaets, T. Hirano*, I. Solovyev** and Y. Suzuki** \\ Electrotechnical Laboratory, Umezono, Tsukuba-shi, 305 Japan \\ * Meiji University, Higashimita, Tama-ku, Kawasaki-shi, 214 Japan \\ ** JRCAT-NAIR, Higashi, Tsukuba-shi, 305 Japan
}

\begin{abstract}
In La0.8- $\mathrm{Bi}_{\mathrm{x}} \mathrm{Sr}_{0.2} \mathrm{MnO}_{3}$ films $(\mathrm{x}=0 \sim 0.3)$ prepared by a laser deposition technique, Magneto-Circular Dichroism (MCD) spectra between 1.5 to $6 \mathrm{eV}$ and temperature dependence of resistivity were investigated. In the films without $\mathrm{Bi}$, three optical transitions between 3 and $5 \mathrm{eV}$ in MCD spectra are confirmed by the fitting. The Bi-doping makes shift these three transitions to higher energy and induces a new transition which shifts to lower energy by increasing of doping content. These transitions are ascribed to the charge transfer transitions from O2p to Mnd $\gamma\left(e_{g}\right)$.
\end{abstract}

\section{INTRODUCTION}

The $\mathrm{LaMnO}_{3}$ is known as an antiferromagnetic insulator. Doping holes makes it a ferromagnetic metal and a structual phase transition from the orthorhombic to the rhombohedral structure take place [1]. The transition to the ferromagnetic metal is thought to due to the double exchange interaction between $\mathrm{Mn}^{3+}$ and $\mathrm{Mn}^{4+}$ through the doped holes. It is known that by doping the Bismuth to this system the electrical resistivity and magneto-optical effect change [2], but the details is not clear. In this paper we report the MCD spectra and the resistivity of Bi-doped $\mathrm{LaO}_{8} \mathrm{Sr}_{0.2} \mathrm{MnO}_{3}$ films by a laser deposition technique and discuss their structures.

\section{RESULTS AND DISCUSSION}

Figure 1 shows the temperature dependence of the electrical resistivity of $\mathrm{La}_{0.8-\mathrm{x}} \mathrm{Bi}_{\mathrm{x}} \mathrm{Sr}_{0.2} \mathrm{MnO}_{3}$ films $(\mathrm{x}=0 \sim 0.3)$. The resistivity of the films with $x=0$ shows the same temperature-dependence as reported for the bulk specimens [1]. The Curie temperature $\mathrm{Tc}$ from a magnetization measurements was nearly equal to the peak in the curve of Fig.1. Figure shows that the peak decreases with increase of $\mathrm{Bi}$. These results shows that for a fixed temperature the metal-insulator transition occurs by Bi-doping. The transition is believed to arise from the increase of $\mathrm{Mn}-\mathrm{O}-\mathrm{Mn}$ bonding angle [3]. Figure 2 shows the MCD spectra at the temperature $T$ of $20 \mathrm{~K}$ and in the applied field $\mathrm{H}$ of $10 \mathrm{kOe}$. These spectra have many peaks. Such magnetic contributions to the optical spectra may be atributed to the transitions related with $3 \mathrm{~d}$ levels. The position of each peak did not change with temperatures below Tc. This figure shows that the energy of each peak systematically changes with $\mathrm{Bi}$ contents.

In order to estimate the energies of the electron transition, the fitting of spectra was tried. MCD spectrum of the film with $x=0$ was well reproduced by three dispersions with the centers at $3.1 \mathrm{eV}, 3.9 \mathrm{eV}$ and $4.7 \mathrm{eV}$, respectively. Figure 3 shows the dispersions obtained from fitting for the $\mathrm{MCD}$ spectrum of $\mathrm{x}=0$ and their synthesizing

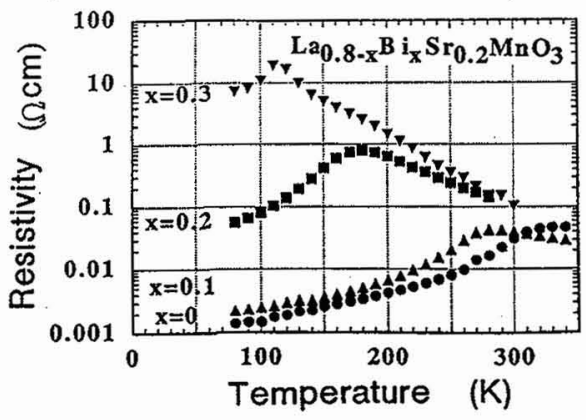

Fig. 1 Temperature dependence of the resistivity for films with various $B i$ contents $x$. 


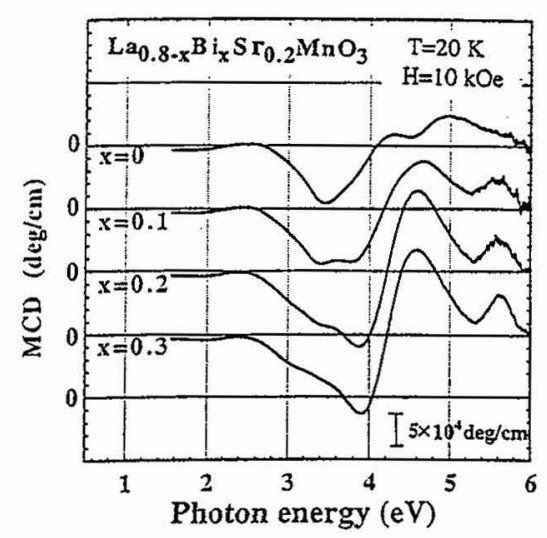

Fig. 2 MCD spectra of films with various $B i$ contents $x$ at $\mathrm{T}=20 \mathrm{~K}$ and $\mathrm{H}=10 \mathrm{kOe}$.

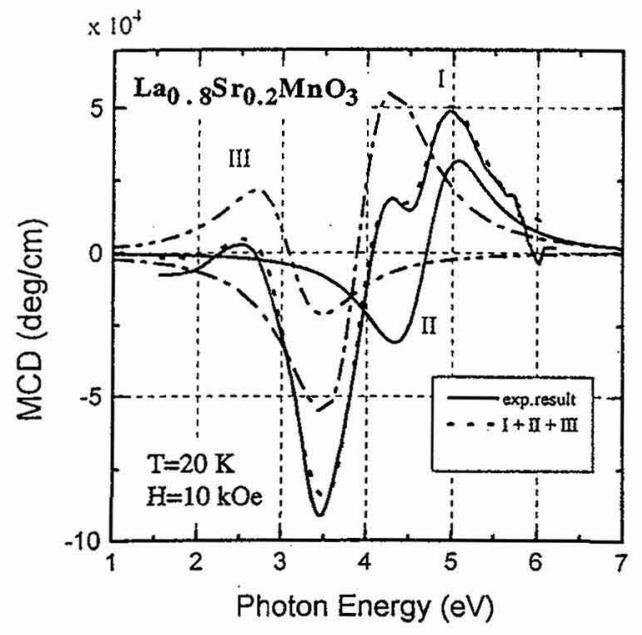

Fig.4 Dispersions obtained from fitting for MCD spectrum of $x=0.1$ and their synthesizing curve. Measured $\mathrm{MCD}$ spectrum is also shown.

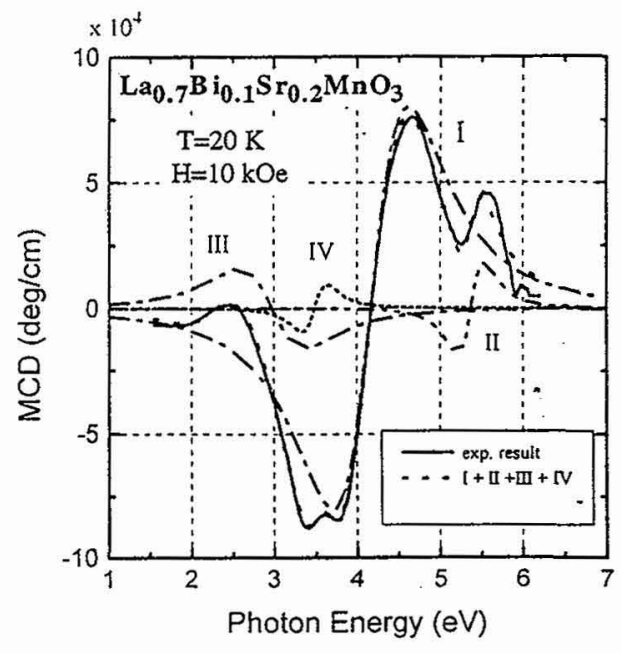

Fig.3 Dispersions obtained from fitting for MCD spectrum of $x=0$ and their synthesizing curve. Measured MCD spectrum is also shown.

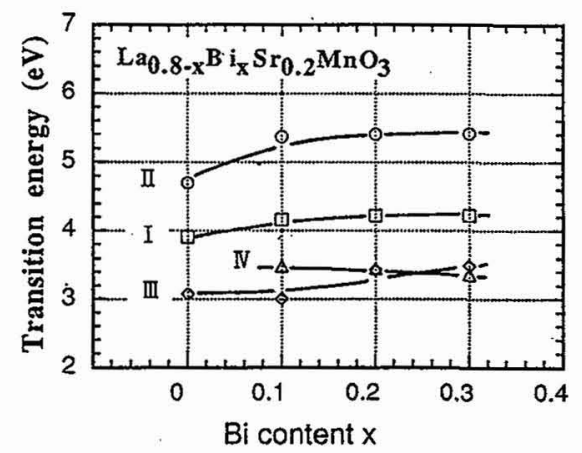

Fig.5 $\mathrm{Bi}$ content dependence of the transition energy determined by the center of each dispersion fitting.

curve. We named these dispersions as dispersion I, I and III. For the film with $\mathrm{Bi}(\mathrm{x} \neq 0)$, the specta were well explained by four dispersions. Figure 4 shows the fitting results for $x=0.1$. The three dispersions, I, II and III shift to higher energy as increasing Bi content, but the new dispersion, IV shifts to lower energy. Figure 5 shows the Bi content dependence of the transition energy determined by the center of each dispersion fitting. These dispersions I, II and II may be ascribed to the charge transfer transition from $\mathrm{O} 2 \mathrm{p}$ to $\mathrm{Mnd} \gamma\left(\mathrm{e}_{\mathrm{g}}\right.$ ), judging from the band structure of $\mathrm{LaMnO}_{3}{ }^{4)}$ and $\mathrm{La}_{1-\mathrm{x}} \mathrm{Bax}_{\mathrm{X}} \mathrm{MnO}_{3}{ }^{5}$. Dispersion $\mathrm{N}$, which newly appears by Bi-doping and shifts to lower energy with increase of $\mathrm{Bi}$ content, is also considered as the charge transfer transition from $\mathrm{O} 2 \mathrm{p}$ to $\mathrm{Mnd} \gamma(\mathrm{eg})$. The shift to lower energy may be ascribed to the decrease of the band width due to the metal-insulator transition.

\section{References}

[1] Y. Tokura, A. Urushibara, Y. Moritomo, T. Arima, A. Asamitu, G. Kido and N. Furukawa: J. Phys.Soc.Jpn, 63 (1994) 3931-3935.

[2] T. J. A. Popma and M. G. J. Kamminga: Solid State Comm.1 7 (1975) 1073-1075.

[3] J. B. Torrance, P. Lacorre and A. I. Nazzal: Phys. Rev. B 45 (1992) 8209-8212.

[4] I. Solovyev, N. Hamada, and K. Terakura: Phys. Rev. B 53 (1996) 7158-7170.

[5] N. Hamada, H. Sawada and K. Terakura: J. Chem. Phys. Solids 56 (1995) 1719-1720. 